(C) The Authors 2017. This is an Open Access article, distributed under the terms of the Creative Commons Attribution licence (http:// creativecommons.org/licenses/by/4.0/), which permits unrestricted re-use, distribution, and reproduction in any medium, provided the original work is properly cited.

\title{
Dairy food supplementation may reduce malnutrition risk in institutionalised elderly
}

\author{
Sandra Iuliano ${ }^{1 *}$, Shirley Poon ${ }^{1}$, Xiaofang Wang ${ }^{1}$, Minh Bui $^{2}$ and Ego Seeman ${ }^{1,3}$ \\ ${ }^{1}$ Department of Endocrinology/Medicine, University of Melbourne/Austin Health, West Heidelberg, VIC 3081, Australia \\ ${ }^{2}$ Melbourne School of Population E Global Health, University of Melbourne, Parkville, VIC 3010, Australia \\ ${ }^{3}$ Institute of Health and Ageing, Australian Catholic University, Melbourne, VIC 3000, Australia \\ (Submitted 18 October 2016 - Final revision received 12 December 2016 - Accepted 14 December 2016 - First published online 18 January 2017)
}

\section{Abstract}

Malnutrition in institutionalised elderly increases morbidity and care costs. Meat and dairy foods are high-quality protein sources so adequate intakes may reduce malnutrition risk. We aimed to determine whether inadequate intakes of meat and dairy foods contribute to malnutrition in institutionalised elderly. This cross-sectional study involved 215 elderly residents $(70 \cdot 2 \%$ females, mean age $85 \cdot 8$ years) from twenty-one agedcare facilities in Melbourne, Australia. Dietary intake was assessed using observed plate waste. Food groups and serving sizes were based on the Australian Guide to Healthy Eating. Nutrient content was analysed using a computerised nutrient analysis software (Xyris). Malnutrition risk was assessed using the Mini Nutrition Assessment (MNA) tool; a score between 24 and 30 indicates normal nutritional status. Data were analysed using robust regression. Mean MNA score was 21.6 (SD 2.7). In total, $68 \%$ of residents were malnourished or at risk of malnutrition (MNA score $\leq 23.5$ ). Protein intake was 87 (SD 28)\% of the Australian recommended dietary intake (RDI). Consumption averaged 1 serving each of dairy foods and meat daily. Number of dairy and meat servings related to proportion of protein RDI (both $P<0 \cdot 001$ ), with the former contributing $13 \%$ and the latter $12 \%$ to protein RDI. Number of dairy servings $(P<0 \cdot 001)$, but not meat servings increased MNA score; each dairy serving was associated with a 1 point increase in MNA score so based on current intakes, on average if residents consumed the recommend four dairy servings (addition of 3 points to MNA score) they would achieve normal nutrition status ( $>24$ points). Provision of meat and dairy foods did not meet recommended levels. On the basis of current dietary intakes in aged-care residents, increasing consumption of dairy foods to the recommended four servings daily ensures protein adequacy and may reduce malnutrition risk in institutionalised elderly, and so reduce risk of comorbidities and costs associated with malnutrition.

Key words: Aged-care facilities: Dairy foods: Elderly: Malnutrition: Mini Nutrition Assessment

Malnutrition in institutionalised elderly is endemic, with up to $89 \%$ of residents being at risk of malnutrition or malnourished ${ }^{(1)}$. Malnutrition is associated with higher morbidity and poorer health outcomes ${ }^{(2)}$. Risk factors for malnutrition in institutionalised elderly include age, sex (female), cognitive impairment, level of dependency, swallowing difficulties and not consuming all foods offered ${ }^{(3)}$. In Australia the majority of institutionalised elderly are women over 80 years of age.

The annual cost of malnutrition in institutionalised elderly in the Netherlands is estimated at $€ 8000$ (approximately US\$900) for each resident at risk of malnutrition and $€ 12000$ (approximately US\$13000) for each malnourished resident ${ }^{(4)}$. Similar analyses are not available in Australia, however in the hospital setting, after controlling for underlying conditions and treatments, malnutrition added about AU $\$ 1800$ (approximately $€ 1200$ or US $\$ 1300$ ) to each admission ${ }^{(5)}$. As the population ages, demand for institutionalised care will increase, and so too will the burden of poor health related to malnutrition in the elderly.
Institutionalised elderly are predominantly reliant on aged-care providers to meet their nutritional needs. Nearly all food is provided through the facility's food service, with most residents having limited access to externally prepared foods. These circumstances necessitate that aged-care providers offer nutritionally adequate meals and snacks. Despite nationally available guidelines and supervision by dietitians to assist staff with menu planning, a study of fourteen aged-care facilities revealed that foods provided do not always meet nutritional requirements, with protein intakes frequently below recommended ${ }^{(6)}$. Meat and alternatives (poultry, fish, eggs, tofu, nuts, seeds, legumes/beans) and dairy foods (milk, yogurt, cheese) provide protein and assist in meeting protein requirements with adequate provision and consumption $^{(7)}$. Therefore we hypothesised that in aged-care residents, inadequate intakes of meat and dairy foods would be associated with protein insufficiency and increased risk of malnutrition.

Abbreviations: BW, body weight; IGF-1, insulin-like growth factor-1; MNA, Mini Nutrition Assessment; RDI, recommended dietary intake.

* Corresponding author: Dr S. Iuliano, fax +6139496 3365, email sandraib@unimelb.edu.au 


\section{Methods}

Data were collected from a convenience sample of ambulant elderly ( $>10 \%$ of all residents) from twenty-one aged-care facilities in metropolitan Melbourne and regional Victoria, Australia, between November 2013 and May 2014 as part of baseline assessments for a large cluster-randomised placebo-controlled trial. Inclusion criteria for the trial were: (i) facilities required accreditation by the Australian Aged-Care Quality Agency, and (ii) they accommodated ambulant residents. Written consent was obtained from residents, or next of kin to monitor dietary intake and perform nutrition assessments. Residents provided written consent to perform blood sampling. The overall study was approved by the Austin Hospital Human Research Ethics committee (project number 04958) and is registered on the Australian New Zealand Clinical Trials Registry (ACTRN12613000228785).

Food service at facilities operate cook-fresh systems, with all foods prepared on-site on the basis of 4-week rotating menus. Typical meal service consisted of a continental-style breakfast (occasional hot breakfast), a mid-day meal providing a hot dish and dessert, an evening meal consisting of soup and choice of a hot or cold dish and dessert, and morning, afternoon and evening snacks.

Trained dietitians determined dietary intake on two random days using the validated method of visual estimation of plate waste ${ }^{(8)}$. Standard serves were weighed on a digital food scale $( \pm 1 \mathrm{~g})$ (Soehnle Page Profi), and foods and beverages served and wasted were compared against the standard serve using a seven-point scale. The seven-point scale represents portions of each food consumed (or remaining): $0=$ no food remaining, $+M=1$ mouthful remaining, $1 / 4=25 \%$ remaining, $1 / 2=50 \%$ remaining, $3 / 4=75 \%$ remaining, $-M=1$ mouthful consumed ( $90 \%$ remaining), $1=$ no food eaten. Meals served were rated against the standard meal (medium given the value of $100 \%$ ); small serving $=75 \%$, large serving $=125 \%$, extra large serving $=150 \%$. Consumption was calculated as the difference between amounts served and wasted.

Foods were categorised into one of the five recommended food groups: vegetables and legumes/beans; fruits; grain (cereal) foods; lean meat, poultry, fish, eggs, tofu, nuts/seeds, legumes/beans (termed 'meat'); and milk, yogurt, cheese and/or alternatives (termed 'dairy') (9). On the basis of Australian Guide to Healthy Eating, if legumes/beans are the protein source (e.g. vegetarian dish), it is classified as 'meat', but in the presence of 'meat' it is classified as a 'vegetable ${ }^{,(9)}$. Legumes/beans made up only $0 \cdot 44 \%$ of all foods consumed (data not shown), and were eaten during meals containing meat, further these were included in the 'vegetables and legumes/beans' food group. Foods not fitting into the five food groups were considered 'discretionary', and these were foods high in energy, saturated fats, added sugars, added salt, or alcohol, for example cakes, biscuits, pastries, spreads, soft drinks, butter, cream, ice cream and processed meats ${ }^{(9)}$. Mixed dishes not considered 'discretionary' were analysed by categorising each ingredient into one of the five food groups.

Nutrient intakes were calculated using a computerised nutritional analysis software (Xyris Software (Australia) Pty Ltd) using product-specific nutritional information on packaging. Where packaging information was not available, nutrient values were derived from NUTTAB $2010^{(10)}$. There were no missing values for energy or protein.
Energy requirements were estimated on the basis of Schofield equation using estimated height from ulna length and applying a physical activity level of $1 \cdot 20^{(11)}$. Protein requirements were based on age- and sex-specific recommended dietary intakes (RDI); males $>70$ years, $1.07 \mathrm{~g} / \mathrm{kg}$ body weight (BW); women $>70$ years, $0.94 \mathrm{~g} / \mathrm{kg} \mathrm{BW}^{(12)}$.

Nutritional status was assessed by a qualified dietitian using the Mini Nutritional Assessment (MNA), a validate tool that consist of eighteen questions related to nutritional status, with a maximum score of $30^{(13)}$. Malnutrition was defined as a score $<17$; at risk of malnutrition for scores between 17 and 23.5; and normal nutritional status for scores between 24 and $30^{(13)}$. When required, nursing or care staff assisted with responses, and objective measures, for example weight changes, obtained from medical records maintained at facilities.

A sub-sample of ninety-two females and thirty-five males underwent morning fasting blood tests analysed for albumin (Cobas 701; Roche), Hb (Sysmex XN20 analyzer; Roche), insulin-like growth factor-1 (IGF-1) (LIAISON), 25-hydroxy vitamin D (25(OH)D) and parathyroid hormone (PTH) (immunochemistry, Cobas E170; Roche).

Distribution of variables was checked for normality using Shapiro-Wilk test. Sex comparisons were conducted using twosample independent $t$ test for normally distributed variables otherwise nonparametric Mann-Whitney test was used. For a categorical variable Fisher's exact test was used. The association between the outcome variables, malnutrition risk (MNA score) or proportion of RDI (\% RDI) for protein and predictors (number of meat or dairy servings), were examined using robust regression. For univariate analyses data were adjusted for sex, age and weight, and for multivariate analyses predictors were also adjusted for each other. All analyses were carried out using Stata 13.1 software (StataCorp LP).

\section{Results}

Data were collected from 215 ambulant residents (70\% females, mean age 85.8 (SD 7.5 ) years). In total, 208 residents were able to self-feed, seven required feeding assistance; 211 residents consumed regular foods, four required texture-modified diets. On the basis of MNA scores, $68 \%$ of residents were malnourished or at risk of malnutrition and mean protein intake provided 87 (SD 28) \% of the RDI (Table 1). Mean albumin (36 (SD 4) g/l), Hb (128 (sD 16) g/l), IGF-1 (16 (sD 6) nmol/l) and 25(OH)D (75 (sD 27) $\mathrm{nmol} / \mathrm{l}$ ) were within the normal reference ranges, whereas mean PTH (6.8 (SD 4.1) pmol/l) was on the upper end of the normal range of 1.6-6.9 pmol/1 (Table 1). Albumin levels were positively related to MNA score $(r 0 \cdot 25, P=0.005)$, but no relationship was observed between IGF-1 and MNA score $(r$ 0.00, $P=0.995)$. MNA score was related to number of medical conditions $(r-0 \cdot 14, P=0 \cdot 039)$, but not number of medications $(r-0 \cdot 11$, $P=0 \cdot 132)$. Each additional medical condition was associated with a 0.14 lower MNA score. As secondary indicators of nutritional adequacy mean intakes of $\mathrm{Fe}$ (men 9.3 (SD 3.8) $\mathrm{mg} / \mathrm{d}$; women 8.1 (sD 2.6$) \mathrm{mg} / \mathrm{d}$ ) met the RDI ( $8 \mathrm{mg} / \mathrm{d}$ for both sexes), but intakes for $\mathrm{Zn}$ (men 7.8 (sD 2.9) $\mathrm{mg} / \mathrm{d}$; women 6.6 (sD 1.9) $\mathrm{mg} / \mathrm{d}$ ) were below the RDI of 14 and $8 \mathrm{mg} / \mathrm{d}$, respectively. 
Table 1. Baseline characteristics, and comparison between elderly males and female aged-care residents $\dagger$ (Mean values and standard deviations)

\begin{tabular}{|c|c|c|c|c|c|c|c|}
\hline & \multicolumn{2}{|c|}{ All $(n$ 215) } & \multicolumn{2}{|c|}{ Female $(n 151)$} & \multicolumn{2}{|c|}{ Male $(n 64)$} & \multirow[b]{2}{*}{$P$} \\
\hline & Mean & SD & Mean & SD & Mean & SD & \\
\hline Age (years) & 85.8 & 7.5 & 86.5 & 6.6 & $84 \cdot 0$ & 8.9 & $0.110^{\star \star}$ \\
\hline Height (m) & 1.64 & 0.08 & 1.60 & 0.05 & 1.73 & 0.05 & $<0.001$ \\
\hline Weight (kg) & 68.9 & $15 \cdot 7$ & $65 \cdot 3$ & $14 \cdot 3$ & 77.5 & $15 \cdot 6$ & $<0.001^{\star \star}$ \\
\hline BMI $\left(\mathrm{kg} / \mathrm{m}^{2}\right)$ & $25 \cdot 6$ & $5 \cdot 3$ & $25 \cdot 5$ & 5.5 & $25 \cdot 9$ & 4.8 & 0.624 \\
\hline Medications $(n)$ & 11.0 & 4.0 & $12 \cdot 0$ & 4.0 & 11.0 & 4.0 & 0.129 \\
\hline Medical conditions $(n)$ & $10 \cdot 0$ & $4 \cdot 0$ & $10 \cdot 0$ & $4 \cdot 0$ & $10 \cdot 0$ & $5 \cdot 0$ & 0.960 \\
\hline Albumin $(g / l)$ & $36 \cdot 0$ & 4.0 & $36 \cdot 0$ & 4.0 & $37 \cdot 0$ & 3.0 & $0.438^{*}$ \\
\hline $\mathrm{Hb}(\mathrm{g} / \mathrm{l})$ & $128 \cdot 0$ & $16 \cdot 0$ & $125 \cdot 0$ & $15 \cdot 0$ & $135 \cdot 0$ & $15 \cdot 0$ & $<0.001^{*}$ \\
\hline IGF-1 (nmol/l) & $16 \cdot 0$ & $6 \cdot 0$ & $16 \cdot 0$ & $6 \cdot 0$ & $15 \cdot 0$ & $6 \cdot 0$ & $0.435^{\star}$ \\
\hline 25(OH)D (nmol/l/) $\ddagger \S$ & $75 \cdot 0$ & $27 \cdot 0$ & $78 \cdot 0$ & $26 \cdot 0$ & $67 \cdot 0$ & $29 \cdot 0$ & $0.032^{*}$ \\
\hline PTH (pmol/l)‡ & $6 \cdot 8$ & $4 \cdot 1$ & 6.5 & $4 \cdot 2$ & $7 \cdot 4$ & $4 \cdot 0$ & $0 \cdot 173^{\star \star}$ \\
\hline MNA score & 21.6 & 3.7 & 21.7 & 3.8 & $21 \cdot 6$ & 3.5 & $0.656^{\star \star}$ \\
\hline Normal/at risk/malnourished (\%) & \multicolumn{2}{|c|}{$32 / 57 / 11$} & \multicolumn{2}{|c|}{$31 / 57 / 12$} & \multicolumn{2}{|c|}{$34 / 58 / 8$} & $0.689^{\star \star \star}$ \\
\hline \multicolumn{8}{|l|}{ Energy intake } \\
\hline $\mathrm{kJ} / \mathrm{d}$ & 6307 & 1514 & 5973 & 1255 & 7075 & 1770 & $<0.001$ \\
\hline $\mathrm{kcal} / \mathrm{d}$ & 1507 & 361 & 1427 & 300 & 1690 & 423 & $<0.001$ \\
\hline$\%$ Estimated energy requirement & 85 & 19 & 87 & 19 & 81 & 20 & 0.068 \\
\hline \multicolumn{8}{|l|}{ Protein intake } \\
\hline$g / d$ & $56 \cdot 0$ & $16 \cdot 0$ & 54.0 & $14 \cdot 0$ & $60 \cdot 0$ & $20 \cdot 0$ & $0.040^{\star *}$ \\
\hline$\%$ RDI & $87 \cdot 0$ & $28 \cdot 0$ & 91.0 & $28 \cdot 0$ & $76 \cdot 0$ & 24.0 & $<0.001^{\star *}$ \\
\hline Per kg body weight & 0.8 & 0.3 & 0.9 & 0.3 & 0.8 & 0.2 & 0.082 \\
\hline Dietary Ca $(\mathrm{mg} / \mathrm{d})$ & 622 & 263 & 612 & 241 & 647 & 317 & $0.852^{\star \star}$ \\
\hline
\end{tabular}

IGF-1, insulin-like growth factor-1; 25(OH)D, 25-hydroxy vitamin D; PTH, parathyroid hormone; MNA, Mini Nutrition Assessment.

$P$-value computed using * $t$ test, ${ }^{* *}$ Mann-Whitney test and ${ }^{* * *}$ Fisher's exact test for sex comparisons.

† Reference ranges: albumin: 32-43 g/l; Hb: 125-175 g/l; IGF-1: 6-27 nmol//; 25(OH)D: 50-250 nmol//; PTH: 1.6-6.9 pmol/l.

$\ddagger n 92$ females and 35 males.

$\S$ In Australia mandatory fortification with vitamin D only occurs in edible oil spreads; $70 \%$ of residents were administered a vitamin D supplement during data collection.

Some sex differences were observed (Table 1). Males were taller and heavier (but did not differ in BMI), consumed more protein daily, but achieved a lower proportion of their protein RDI than women. Men also tended towards meeting less of their estimated energy requirement, and consumed less protein $/ \mathrm{kg}$ BW than women. Mean 25(OH)D was lower in males than females, and mean PTH in males was above the normal range (1.6-6.9 pmol/1). Mean Hb levels were within normal levels for both sexes relative to their sex-specific ranges. Males and females did not differ in the number of medical conditions or prescribed medications

Mean intake of meats and dairy were 1.0 (SD 0.6 ) and 1.1 (sD 0.7 ) servings/d, respectively, both below the recommended intake levels of 2 and 4 servings/d for older women and 2.5 and 3.5 servings/d for older men, respectively ${ }^{(9)}$. Mean serves provided, wasted and consumed of each food group are presented in Table 2. Mean servings of meats and dairy foods provided did not meet the recommended levels. Food waste for meat was $0 \cdot 3$ (SD 0.3) (20.5 (SD 24.0)\%) servings and 0.2 ( $\mathrm{SD} 0.3$ ) (13.9 (SD $17 \cdot 7$ ) \%) servings for dairy.

For both univariate and multivariate (adjusted for age, sex and weight) regression analyses number of dairy and meat servings consumed was associated with proportion of protein RDI met $(P<0 \cdot 001)$. Each dairy serving contributed $13 \%$ and meat serving $12 \%$ protein RDI, so on average residents would achieve 100 and $99 \%$ of the RDI for protein, respectively, with an additional dairy or meat serving above current consumption (Table 3). Univariate analysis indicated only number of dairy servings $(P=0.004)$ was associated with MNA score (Table 3). Each dairy serving contributed 1 point on the MNA score, so within the context of their current dietary intake, if residents consumed the recommended four dairy servings daily they would, on average, achieve normal nutritional status (MNA score $>24$ ) and only $1 / 3$ of residents would be classified as malnourished or at risk of malnutrition (data not shown). Including number of medical conditions or those requiring feeding assistance or a texture-modified diet to the models did not alter outcomes.

\section{Discussion}

In all, $68 \%$ of these institutionalised elderly were considered malnourished or at risk of malnutrition. Prevailing intakes of meats and dairy servings did not meet recommended levels. Consuming inadequate dairy servings contributed to risk of malnutrition and inadequate protein intake, whereas consuming insufficient meat servings influenced adequacy of protein intake. Provision of meats and dairy did not meet recommended levels.

The rates of malnutrition observed were similar to previous reports $^{(1)}$. Malnutrition is associated with greater morbidity, so in addition to direct costs of malnutrition, indirect costs are likely, due to greater care needs, and protracted hospitalisation with more complications ${ }^{(2)}$. Preventing malnutrition will likely have cost-saving benefits for aged-care providers and the health system.

Mean protein intakes in residents were below recommended levels ${ }^{(12)}$. Protein malnutrition exacerbates aged-related loss of 
Table 2. Mean number of serves provided, wasted and consumed daily by 215 elderly residents from twenty-one aged-care facilities

(Mean values and standard deviations)

\begin{tabular}{|c|c|c|c|c|c|c|c|c|}
\hline \multirow[b]{2}{*}{ Food groups } & \multirow{2}{*}{\multicolumn{2}{|c|}{ Recommendations $>70$ years old }} & \multicolumn{2}{|c|}{ Provided } & \multicolumn{2}{|c|}{ Wasted } & \multicolumn{2}{|c|}{ Consumed } \\
\hline & & & Mean & SD & Mean & SD & Mean & SD \\
\hline \multirow[t]{2}{*}{ Vegetables } & Male & 5 & 3.6 & 1.9 & 0.7 & 1.0 & $2 \cdot 9$ & 1.5 \\
\hline & Female & 5 & $3 \cdot 3$ & 1.3 & 0.8 & 0.7 & 2.5 & $1 \cdot 2$ \\
\hline \multirow[t]{2}{*}{ Fruits } & Male & 2 & $2 \cdot 2$ & $1 \cdot 1$ & 0.4 & 0.4 & 1.8 & $1 \cdot 1$ \\
\hline & Female & 2 & 1.8 & 0.9 & 0.3 & 0.4 & 1.6 & 0.8 \\
\hline \multirow[t]{2}{*}{ Grains (cereals) } & Male & 4.5 & 3.4 & 1.6 & 0.5 & 0.6 & $2 \cdot 9$ & 1.6 \\
\hline & Female & 3 & 3.0 & 1.2 & 0.6 & 0.6 & $2 \cdot 4$ & 1.0 \\
\hline \multirow[t]{2}{*}{ Meat } & Male & 2.5 & 1.4 & 0.7 & 0.2 & 0.3 & $1 \cdot 2$ & 0.7 \\
\hline & Female & 2 & 1.2 & 0.6 & 0.3 & 0.4 & 0.9 & 0.5 \\
\hline \multirow[t]{2}{*}{ Dairy } & Male & 3.5 & 1.3 & 0.7 & 0.1 & 0.2 & 1.1 & 0.7 \\
\hline & Female & 4 & 1.3 & 0.7 & 0.2 & 0.3 & 1.1 & 0.6 \\
\hline \multirow[t]{2}{*}{ Discretionary } & Male & $0-2.5$ & $6 \cdot 9$ & $2 \cdot 8$ & 0.8 & 0.8 & $6 \cdot 0$ & $2 \cdot 7$ \\
\hline & Female & 0-2 & 5.8 & $2 \cdot 1$ & 1.0 & $1 \cdot 1$ & 4.8 & 1.7 \\
\hline
\end{tabular}

Serving sizes; meat: $65 \mathrm{~g}$ cooked lean meat, $80 \mathrm{~g}$ cooked lean poultry, $100 \mathrm{~g}$ cooked fish fillet, two large eggs, one cup cooked/canned legumes, $170 \mathrm{~g}$ tofu, $30 \mathrm{~g}$ nuts or seeds; dairy foods: $250 \mathrm{ml}$ milk, $200 \mathrm{~g}$ yogurt, $40 \mathrm{~g}$ cheese, 1/2 cup evaporated milk or ricotta cheese; vegetables: $1 / 2$ cup cooked vegetables, sweet corn or cooked, dried or canned beans, peas, lentils, one cup green leafy or raw salad vegetable, $1 / 2$ potato or starchy vegetable, one medium tomato; fruits: one medium or two small fruits, one cup diced or canned fruits; grains: one slice bread, $1 / 2$ bread roll, $1 / 2$ cup cooked, pasta, rice, noodles, porridge, 2/3 cup cereal flakes, 1/4 cup muesli, three crispbreads, one crumpet, one English muffin or scone; discretionary: two scoops ice cream, two slices processed meats, two thin sausages, two to three sweet biscuits, one doughnut, five to six lollies, one small slice of cake, two tablespoons honey or jam, 1/2 small bar of chocolate, two tablespoons cream, one tablespoon margarine or butter, 1/3 commercial meat pie, twelve fried chips, two standard alcoholic drinks ${ }^{(9)}$.

Table 3. Robust regression fitted to the data to examine the relationship between malnutrition risk score (MNA) or proportion of recommended protein intake (\% RDI) and dairy and meat consumed by elderly aged-care residents

\begin{tabular}{|c|c|c|c|c|c|c|c|}
\hline \multirow[b]{2}{*}{ Outcome } & \multirow[b]{2}{*}{ Predictor } & \multicolumn{3}{|c|}{ Univariate } & \multicolumn{3}{|c|}{ Multivariate } \\
\hline & & Coefficient & SE & $P$ & Coefficient & SE & $P$ \\
\hline \multirow[t]{2}{*}{ MNA } & Dairy serves eaten & 1.05 & 0.36 & 0.004 & & & \\
\hline & Meat serves eaten & 0.45 & 0.43 & 0.296 & & & \\
\hline \multirow[t]{2}{*}{ \% RDI } & Dairy serves eaten & $12 \cdot 5$ & $2 \cdot 18$ & $<0.001$ & $13 \cdot 2$ & 1.98 & $<0.001$ \\
\hline & Meat serves eaten & 11.2 & 2.63 & $<0.001$ & $12 \cdot 1$ & $2 \cdot 36$ & $<0.001$ \\
\hline
\end{tabular}

muscle mass and function, and adequate protein may prevent muscle loss ${ }^{(14)}$. Houston et al. ${ }^{(15)}$ observed in over 2000 elders (aged 70-79 years) that those in the highest quintile for energyadjusted protein intake (approximately $1 \cdot 1 \mathrm{~g} / \mathrm{kg} \mathrm{BW}$ per d) lost $40 \%$ less total and appendicular lean mass over 3 years compared with those in the lowest quintile (approximately $0.7 \mathrm{~g} / \mathrm{kg} \mathrm{BW}$ per d).

Some investigators suggest that the recommended protein intake of $0.75-1.0 \mathrm{~g} / \mathrm{kg}$ BW per $\mathrm{d}$ for the elderly may be insufficient to maintain lean mass, and intakes between 1.0 and $1.3 \mathrm{~g} / \mathrm{kg} \mathrm{BW}$ per $\mathrm{d}$ are required to maintain $\mathrm{N}$ balance in the elderly, because of age-related anabolic resistance and reduced protein synthesis efficiency ${ }^{(12,1)}$. For elderly with acute or chronic diseases, intakes of $1.2-1.5 \mathrm{~g} / \mathrm{kg}$ BW per $\mathrm{d}$ are considered tolerable, except for those with end stage renal failure $^{(17)}$. Inflammation, associated with illness, injury or disease increases energy requirement, impairs protein utilisation and increases $\mathrm{N}$ excretion thus increasing protein needs. For elderly in aged-care mild to moderate inflammation may be present due to chronic disease or illness and may increase protein requirements. van Nie-Visser et $a l .{ }^{(18)}$ observed in nearly 20000 agedcare residents that mean number of diseases was associated with malnutrition. We also observed an association between number of medical conditions and MNA score; however, in aged-care malnutrition may also relate to inadequate intake, so improving intake would likely improve nutritional status in residents ${ }^{(6,19)}$. Provision of meat and dairy did not meet recommended levels impeding the ability for residents to consume adequate dietary protein.

Both meat and dairy are sources of leucine, reported to increase IGF-1, muscle protein synthesis and lean muscle in the elderly, so consumption of these foods may help prevent agerelated muscle loss ${ }^{(20)}$. Kramer et al. ${ }^{(21)}$ indicated that $21 \mathrm{~g}$ of whey protein ( $3 \mathrm{~g}$ of leucine) was sufficient to stimulate muscle protein synthesis in elderly (approximately 81 years of age) sarcopenic men. Low appendicular muscle is an indicator of poor nutritional status, which is captured in the MNA tool as calf and upper arm circumferences.

Although some authors suggest the provision of large amounts of protein in one main meal is sufficient to maximise muscle protein synthesis, others suggest protein intake should be evenly distributed throughout the day ${ }^{(22,23)}$. However, in contrast to these studies where protein intakes met or exceeded recommended levels, mean protein intake in our institutionalised 
elderly was inadequate, including leucine intake being below the suggested threshold to promote muscle protein synthesis. Correcting protein inadequacy may be required first before apparent benefits of protein distribution may be evident.

Residents consumed over 6 servings/d of discretionary foods, well in excess of the recommended 0-2 servings ${ }^{(9)}$. Consumption of discretionary foods in place of meat and dairy options, may limit the ability for residents to obtain sufficient protein, especially for those with reduced appetites ${ }^{(6)}$. Mila et al. ${ }^{(7)}$ observed in a sample of sixty-two Spanish nursing home residents, that with provision (and consumption) of adequate dairy and meat, residents met protein requirements. In contrast, Iuliano et al. ${ }^{(19)}$ reported that $61 \%$ of 199 elderly from eighteen aged-care facilities consumed below recommended protein levels when consuming adequate meat, but inadequate dairy.

Strategies have been explored to improve protein intake and reduce malnutrition risk in institutionalised elderly. Meta-analyses of oral protein supplements (OPS) use in agedcare residents indicate weight gain of approximately 2.5 (95\% CI $1.7,2.7) \%$, but few studies reported improvements to lean mass and physical function ${ }^{(24)}$. In aged-care OPS are often not delivered according to treatment plans and significant waste is observed $^{(25)}$. Moreover, elderly with limited appetites may have difficulty in consuming supplements in addition to regular meals so normal intake may be compromised ${ }^{(24)}$. In a 6-week randomised pilot nutrition intervention, Simmons et al. ${ }^{(26)}$ observed a significant reduction in mealtime energy intake $(-124 \mathrm{kcal} / \mathrm{d}, P<0.05)$ by eighteen nursing home residents when consuming supplements, resulting in no change to total intake. The authors observed a high rate of refusal of supplements raising uncertainty about long-term use of OPS to manage malnutrition.

Limited success with protein fortification of the food supply has been observed in aged-care. Grieger \& Nowson ${ }^{(27)}$ investigated the provision of fortified milk in aged-care, and observed that without supervision and guidance, food service staff did not make sufficient menu modifications to increase milk intake, so no benefits were observed in nutritional status of residents. In an intervention trial in aged-care, Iuliano et al. ${ }^{(28)}$ reported that food service staff had difficulties mixing a dairy-based protein supplement into foods, limiting the quantity of protein provided. Pre-fortified products have been effective in improving nutritional status in institutionalised elderly but budgetary constraints may limit their use ${ }^{(29)}$. However, a cost-benefit analysis of enhanced dietary protein intake on malnutrition risk has not been undertaken, commercially available protein powders cost over four times that of protein from milk powder (approximately AU\$8.00 v. $<\$ 2.00$ for $100 \mathrm{~g}$ of protein), so may be feasible within limited budgets.

The provision of adequate meat and dairy foods is a reasonable approach to improving nutritional status of institutionalised elders. There are limited data on additional meat consumption to prevent malnutrition. A $50 \%$ increase in muscle protein synthesis was observed in elders aged 68 (SD 2) years when consuming 113 ( $n$ 10) or $340 \mathrm{~g}(n 7)$ of beef ${ }^{(30)}$. Muscle protein synthesis was no greater with $340 \mathrm{~g}$ of beef therefore the authors suggested that meals containing about $30 \mathrm{~g}$ of protein (from meat) were sufficient ${ }^{(30)}$.

Improvements in nutritional intake were observed in sixtyeight aged-care residents when consuming two additional dairy servings daily ${ }^{(31)}$. Relative to residents consuming from regular menus ( $n$ 60), increased daily intakes were observed for energy (+900 kJ (215 kcal), $P<0.001)$, protein $(+25 \mathrm{~g}, P<0.0001)$ and proportion of estimated energy requirements ( $+18 \%$, $P<0.0001)$. Protein and energy intakes remained below recommended levels in controls ${ }^{(31)}$. The long-term sustainability of menu changes to improve protein intake in institutionalised elders requires investigation.

The type of dairy food may also influence contribution of dairy, but not meat, to MNA score. Both meat and dairy are sources of quality protein; however, relative to MNA score, increasing milk intake contributes to both protein and fluid intakes, so each additional serving of milk has the capacity to add 1.5 points to the total MNA score. Moreover in line with dietary recommendations current meat intake in residents is approximately half the recommended two servings, so the addition of a meat serve will achieve recommended levels (but not alter MNA score) but dairy intake is approximately $25 \%$, with only one of the recommended four servings being consumed. Three additional dairy serves to current intake levels improves intake to recommended levels in line with the Australian Guide to Healthy Eating.

Food provision in aged-care in Australia is comparable between providers with similar menu cycles and foods offered, so two random days of intake data suitably represents food consumption in residents. Food groups and serving sizes were based on Australian standards, however, serving sizes are similar to other countries so translation of outcomes is reasonable.

In conclusion, rates of malnutrition in elderly in aged-care remain unacceptably high. Dietary strategies in aged-care should aim to improve protein intake and prevent malnutrition in residents. The provision of dairy foods, in line with recommended intake levels is likely a simple and cost-effective method that may reduce malnutrition risk in institutionalised elderly.

\section{Acknowledgements}

The authors thank dietitians; Anishya Gangadharan, Annemarie Murrell, Caryn Batchelor, Deanna Lavanty, Ella Smits, Lexie Griffin, Stephanie Renehan for assisting in data collection, and Marta Van Loan and Lars Rejnmark for their input into the manuscript preparation.

This study was supported by grants from Dairy Australia (grant number TP 701722), California Dairy Research Foundation, National Dairy Council, Aarhus University Hospital and Danish Dairy Research Foundation, Fonterra Co-operative Group Ltd, Dutch Dairy Association and the Dairy Council of California. The funders played no role in the design, execution or analysis of this data.

S. I. was responsible for study design, manuscript content and final preparation of the manuscript; S. P. conducted the research and managed the data; X. W. and M. B. analysed the data and 
performed statistical analysis; and E. S. was involved in study design and manuscript preparation.

The authors declare that there are no conflicts of interest.

\section{References}

1. Borgstrom Bolmsjo B, Jakobsson U, et al. (2015) The nutritional situation in Swedish nursing homes - a longitudinal study. Arch Gerontol Geriatr 60, 128-133.

2. Kuikka LK, Salminen S, Ouwehand A, et al. (2009) Inflammation markers and malnutrition as risk factors for infections and impaired health-related quality of life among older nursing home residents. J Am Med Dir Assoc 10, 348-353.

3. Tamura BK, Bell CL, Masaki KH, et al. (2013) Factors associated with weight loss, low BMI, and malnutrition among nursing home patients: a systematic review of the literature. J Am Med Dir Assoc 14, 649-655.

4. Meijers JM, Halfens RJ, Wilson L, et al. (2012) Estimating the costs associated with malnutrition in Dutch nursing homes. Clin Nutr 31, 65-68.

5. Rowell DS \& Jackson TJ (2011) Additional costs of inpatient malnutrition, Victoria, Australia, 2003-2004. Eur J Health Econ 12, 353-361.

6. Woods J, Walker K, Iuliano-Burns S, et al. (2009) Malnutrition on the menu: nutritional status of institutionalised elderly Australians in low-level care. J Nutr Health Aging 13, 693-698.

7. Mila R, Abellana R, Padro L, et al. (2012) High consumption foods and their influence on energy and protein intake in institutionalized older adults. J Nutr Health Aging 16, $115-122$.

8. Sherwin A, Nowson CA, McPhee J, et al. (1988) Nutrient intake as meals in residential care facilities at the aged: validated visual estimation of plate waste. Aust J Nutr Diet 55, 188-193.

9. Department of Health and Ageing, Australian Government (2015) Australian guide to healthy eating. www.eatforhealth. gov.au (accessed November 2015).

10. Food Standards Australia New Zealand (FSANZ) (2010) Nutrient Tables for use in Australia (NUTTAB). www.food standards.gov.au/science/monitoringnutrients/nutrientables/ Pages/default.aspx (accessed November 2015).

11. Schofield WN (1985) Predicting basal metabolic rate, new standards and review of previous work. Hum Nutr Clin Nutr 39, Suppl. 1, 5-41.

12. Department of Health and Ageing, NHMRC (2006) Nutrient reference values for Australia and New Zealand. Canberra: Australian Government Printer.

13. Guigoz Y, Lauque S \& Vellas BJ (2002) Identifying the elderly at risk for malnutrition. The Mini Nutritional Assessment. Clin Geriatr Med 18, 737-757.

14. Muscaritoli M, Anker SD, Argiles J, et al. (2010) Consensus definition of sarcopenia, cachexia and pre-cachexia: joint document elaborated by Special Interest Groups (SIG) 'cachexia-anorexia in chronic wasting diseases' and 'nutrition in geriatrics'. Clin Nutr 29, 154-159.

15. Houston DK, Nicklas BJ, Ding J, et al. (2008) Dietary protein intake is associated with lean mass change in older, community-dwelling adults: the Health, Aging, and Body Composition (Health ABC) study. Am J Clin Nutr 87, 150-155.

16. Gaffney-Stomberg E, Insogna KL, Rodriguez NR, et al. (2009) Increasing dietary protein requirements in elderly people for optimal muscle and bone health. J Am Geriatr Soc 57, 1073-1079.

17. Bauer J, Biolo G, Cederholm T, et al. (2013) Evidence-based recommendations for optimal dietary protein intake in older people: a position paper from the PROT-AGE Study Group. J Am Med Dir Assoc 14, 542-559.

18. van Nie-Visser NC, Meijers J, Schols J, et al. (2014) Which characteristics of nursing home residents influence differences in malnutrition prevalence? An international comparison of The Netherlands, Germany and Austria. Br J Nutr 111, 1129-1136.

19. Iuliano S, Olden A \& Woods J (2013) Meeting the nutritional needs of elderly residents in aged-care: are we doing enough? J Nutr Health Aging 17, 503-508.

20. Dillon EL, Sheffield-Moore M, Paddon-Jones D, et al. (2009) Amino acid supplementation increases lean body mass, basal muscle protein synthesis, and insulin-like growth factor-I expression in older women. J Clin Endocrinol Metab 94, $1630-1637$.

21. Kramer IF, Verdijk LB, Hamer HM, et al. (2016) Both basal and post-prandial muscle protein synthesis rates, following the ingestion of a leucine-enriched whey protein supplement, are not impaired in sarcopenic older males. Clin Nutr 16, 31263-31268.

22. Bouillanne O, Curis E, Hamon-Vilcot B, et al. (2013) Impact of protein pulse feeding on lean mass in malnourished and at-risk hospitalized elderly patients: a randomized controlled trial. Clin Nutr 32, 186-192.

23. Mamerow MM, Mettler JA, English KL, et al. (2014) Dietary protein distribution positively influences $24-\mathrm{h}$ muscle protein synthesis in healthy adults. $J$ Nutr 144, 876-880.

24. Milne AC, Avenell A \& Potter J (2006) Meta-analysis: protein and energy supplementation in older people. Ann Intern Med 144, 37-48.

25. Simmons SF \& Patel AV (2006) Nursing home staff delivery of oral liquid nutritional supplements to residents at risk for unintentional weight loss. J Am Geriatr Soc 54, $1372-1376$

26. Simmons SF, Zhuo X \& Keeler E (2010) Cost-effectiveness of nutrition interventions in nursing home residents: a pilot intervention. J Nutr Health Aging 14, 367-372.

27. Grieger JA \& Nowson CA (2009) Use of calcium, folate, and vitamin $\mathrm{D}$ (3)-fortified milk for 6 months improves nutritional status but not bone mass or turnover, in a group of Australian aged care residents. J Nutr Elder 28, 236-254.

28. Iuliano-Burns S, Woods J, King K, et al. (2012) A dairy-based protein, calcium and vitamin $\mathrm{D}$ supplement reduces falls and femoral neck bone loss in aged care residents: a cluster randomised trial. J Aging Res Clin Pract 2, 141-146.

29. Strathmann S, Lesser S, Bai-Habelski J, et al. (2013) Institutional factors associated with the nutritional status of residents from 10 German nursing homes (ErnSTES study). J Nutr Health Aging 17, 271-276.

30. Symons TB, Sheffield-Moore M, Wolfe RR, et al. (2009) A moderate serving of high-quality protein maximally stimulates skeletal muscle protein synthesis in young and elderly subjects. J Am Diet Assoc 109, 1582-1586.

31. Iuliano S, Woods J \& Robbins J (2013) Consuming two additional serves of dairy food a day significantly improves energy and nutrient intakes in ambulatory aged care residents: a feasibility study. J Nutr Health Aging 17, 509-513. 